OPEN ACCESS

Edited by:

Silvia Gabrielli,

Bruno Kessler Foundation (FBK), Italy

Reviewed by:

Victoria E. Cosgrove,

Stanford University, United States

Tina Jaeckle

Walden University, United States

*Correspondence:

Jill K. Jones

jkj15@duke.edu

Specialty section:

This article was submitted to Child and Adolescent Psychiatry,

a section of the journal

Frontiers in Pediatrics

Received: 01 July 2020 Accepted: 04 January 2021

Published: 04 February 2021

Citation:

Jones JK, Evans JF and Barfield RC (2021) The Utility of Verbal Therapy for

Pediatric Cancer Patients and

Survivors: Expressive Writing, Video

Narratives, and Bibliotherapy

Exercises. Front. Pediatr. 9:579003.

doi: 10.3389/fped.2021.579003

\section{The Utility of Verbal Therapy for Pediatric Cancer Patients and Survivors: Expressive Writing, Video Narratives, and Bibliotherapy Exercises}

\author{
Jill K. Jones ${ }^{1,2 *}$, John F. Evans ${ }^{2}$ and Raymond C. Barfield ${ }^{3}$ \\ ${ }^{1}$ Trinity College of Arts \& Sciences, Duke University, Durham, NC, United States, ${ }^{2}$ Duke Integrative Medicine, Durham, NC, \\ United States, ${ }^{3}$ Memorial Health University Medical Center (Palliative Care), Savannah, GA, United States
}

Childhood cancer is a stressful experience. No pediatric patient, however, should be made to feel as if their concerns and feelings about their cancer experience must be bottled up inside. Importantly, talking and writing about one's illness has myriad implications for young cancer patients and survivors. The most salient of these may include increased understanding of one's condition as well as improved physical and cognitive symptoms (e.g., lowered depression, decreased anxiety, and an enhanced quality of life overall). This literature review explores three promising avenues for verbal therapy in the pediatric oncology setting: expressive writing, video narratives, and bibliotherapy exercises. Several recent studies, covering verbal therapy methods from illness blogging to book interventions, are referenced and discussed. Ultimately, we conclude that expressive writing, video narratives, and bibliotherapy exercises are valuable, feasible, inexpensive, and acceptable tools for patients and survivors of childhood cancer to facilitate self-expression-and to find meaning in the uncertainty and anxiety that cancer inherently fosters. We recommend that future studies investigate this theme so that we may improve quality of life and mental health for pediatric cancer patients and survivors worldwide.

Keywords: expressive writing, video narratives, bibliotherapy, pediatric cancer, resilience, well-being

\section{INTRODUCTION}

In 2005, a review by Patenaude and Kupst found that up to $20 \%$ of pediatric cancer survivors experience moderate-to-severe posttraumatic stress due to their illness. A much larger percentage of pediatric cancer patients struggles with academics, social relationships, and self-esteem during and after their cancer treatment (1). In facing these challenges, perhaps the most useful tool is one that almost all of us have ready access to: our own language.

Verbal therapy, or expressing one's self through words, can help pediatric cancer patients and survivors find closure and foster personal growth. Here, we review the current literature on the utility of three promising forms of verbal therapy-expressive writing, video narratives, and bibliotherapy exercises-in pediatric oncology. First, we present a summary of each form. Then, we differentiate these forms from the more traditional "talk therapy" (traditional psychotherapy), 
synthesize the findings of 12 most relevant studies (Table 1), and discuss implications for their broader use with pediatric cancer patients and survivors. By encouraging individuals to process their deepest thoughts and feelings about their illness experience (specifically in narrative form), we argue that expressive writing, video narratives, and bibliotherapy exercises can positively impact feelings of stress and anxiety, interpersonal relationships, and overall quality of life for this subpopulation.

\section{Expressive Writing}

Expressive writing (EW) was pioneered by Pennebaker in the early 1980s (12). The traditional EW paradigm (Figure 1) lasts 4 days, asking participants to reflect on one trauma-centered writing prompt for approximately $20 \mathrm{~min} /$ day (13). Across a variety of populations, many studies have demonstrated strong correlations between EW and lower levels of depression, lower levels of pain and medication use, and a positive, stable increase in $\operatorname{mood}(14,15)$. In a meta-analysis of 13 EW studies, Smyth (16) examined consequent outcomes for physical health, psychological well-being, physiological functioning, and general functioning and found a strong, significant effect size $(d=0.47$, $p<0.001)$.

Excitingly, EW has shown particular promise with specific subpopulations of individuals, such as pediatric cancer patients and survivors. These include, but are not limited to the following: individuals with irritable bowel syndrome (17), postdeployment military couples (18), women with a history of childhood sexual abuse (19), and women with breast cancer (20-25). In later sections of this review, we evaluate four studies on EW and its related forms (narrative writing, illness blogs, and online illness support groups) in the pediatric oncology setting.

\section{Video Narratives}

A video narrative is a recording of someone talking about an influential event or situation in their life. This recorded story can later be played back, reflected upon, and/or shared with other people on a video-sharing platform (e.g., YouTube). Synonyms for video narratives, a relatively new therapeutic approach, include video testimonials, testimonial videos, and therapeutic film-making $(7,8)$. Here, we review five publications on the use of video narratives for self-reflection among pediatric cancer patients and survivors.

\section{Bibliotherapy Exercises}

Dating back to ancient Greece, bibliotherapy is defined as the use of books as therapy in the context of mental or physical illness (26). Clients are assigned or offered reading material that is highly relevant to their own personal challenges, ranging from self-help books to memoirs written by individuals with similar backgrounds. Recent studies suggest that bibliotherapy can promote myriad positive effects for young people facing hardship. These range from increased empathy among aggressive elementary school children (27) to improvements in self-concept and peer perceptions among average elementary schoolers (28) to clinically significant changes in anxiety severity among children with nighttime fears (29). In this review, we discuss Schneider's seminal 2012 study on bibliotherapy for children with cancer, bolstered by support from two other publications on bibliotherapy with various cancer patient populations.

\section{Talk Therapy}

In talk therapy, or traditional psychotherapy, a mental health professional asks probing questions and engages in thoughtprovoking conversation with a client to help them address an issue in their life (30). Contemporary randomized controlled trials (RCTs) suggest that talk therapy can significantly reduce feelings of anxiety, depression, and other symptoms of psychological distress among adult cancer patients (3133). Although a dearth of RCTs on talk therapy for pediatric cancer patients and survivors exists, several case vignettes (34, $35)$, reports on adolescent cancer support groups (36, 37), and studies on psychotherapy-influenced interviews (38-40) with this subpopulation have been conducted. Taken together, these studies demonstrate that for younger cancer patients and survivors, talking with others about their disease can help them come to terms with their cancer experience and form meaningful social bonds.

However, there are several caveats to talk therapy's widespread acceptance and accessibility. In 2019, Nitzburg and Farber (41) surveyed 267 adult clients of Talkspace (a text-based, online psychotherapy initiative) about perceived barriers to engaging in traditional, face-to-face talk therapy. Of respondents, $54.2 \%$ reported that traditional talk therapy is too expensive (often $\sim \$ 100 / 1$-h session), and $38.3 \%$ indicated that this verbal therapy is not covered by their insurance; $42.1 \%$ also reported that traditional talk therapy is too time-consuming or inconvenient (e.g., including time traveled to and from their therapist's office), while $27.9 \%$ said they had never found talk therapy particularly helpful. It is our firm belief that EW, video narrative production, and bibliotherapy overcome these issues. In contrast to traditional talk therapy, these verbal therapies can be conducted on patients' own time, at little to no cost, and with very few resources (e.g., a pen and paper, a camera, and/or books). Children and teens may find them especially appealing due to their focus on creative and open storytelling, as well as their novelty; EW, video narrative production, and bibliotherapy are not as well known nor as well studied as traditional psychotherapy. For these reasons, we have chosen to focus on EW, video narrative production, and bibliotherapy for pediatric cancer patients and survivors over traditional talk therapy in this review.

\section{METHODS}

The following terms were searched on Google Scholar, yielding the following results as of 16 January 2020:

- “expressive writing" "pediatric cancer"-108 results, 6 selected - "expressive writing" "pediatric patients"-84 results, 7 selected - "expressive writing" "children" "disease"-4,110 results, 1 selected

- "bibliotherapy" "pediatric cancer patients"-55 results, 4 selected 
TABLE 1 | Studies explored in-depth in this literature review.

\begin{tabular}{|c|c|c|c|c|}
\hline Study & Genre & Country & Modality & Relevant one-sentence summary \\
\hline $\begin{array}{l}\text { Anzeneder et al. } \\
\text { (2018) }\end{array}$ & $\begin{array}{l}\text { Exploratory } \\
\text { intervention }\end{array}$ & Italy & Expressive writing & $\begin{array}{l}\text { Expressive writing had positive effects on perceived quality of life, } \\
\text { internalized symptoms, and coping skills for three out of four } \\
\text { adolescent brain tumor patients in the study. }\end{array}$ \\
\hline Chaparro (2) & $\begin{array}{l}\text { Exploratory } \\
\text { intervention }\end{array}$ & Canada & $\begin{array}{l}\text { Expressive } \\
\text { writing, } \\
\text { psychotherapy- } \\
\text { influenced } \\
\text { interview }\end{array}$ & $\begin{array}{l}\text { Pediatric cancer survivors completed psychotherapy-influenced } \\
\text { phone interviews while many of their mothers completed expressive } \\
\text { writing exercises, illuminating positive correlations between meaning } \\
\text { making, "cancer talk" frequency, distress-related disclosure, and } \\
\text { posttraumatic growth. }\end{array}$ \\
\hline $\begin{array}{l}\text { Keim-Malpass } \\
\text { et al. (3) }\end{array}$ & $\begin{array}{l}\text { Exploratory } \\
\text { qualitative analysis }\end{array}$ & USA & $\begin{array}{l}\text { Expressive writing } \\
\text { (illness blogs) }\end{array}$ & $\begin{array}{l}\text { Thematic analysis of seven adolescent cancer blogs granted personal } \\
\text { insight into unique cancer experiences while pointing to the creative } \\
\text { and psychosocial benefits of writing about illness. }\end{array}$ \\
\hline $\begin{array}{l}\text { Crook and Love } \\
\text { (4) }\end{array}$ & $\begin{array}{l}\text { Exploratory } \\
\text { qualitative analysis }\end{array}$ & USA & $\begin{array}{l}\text { Expressive writing } \\
\text { (online support } \\
\text { groups) }\end{array}$ & $\begin{array}{l}\text { Qualitative analysis of messages in an online cancer support group } \\
\text { elucidated both disadvantages (spreading medical misinformation, } \\
\text { lack of synchronous communication) and advantages (space for } \\
\text { venting healthcare frustrations and connecting with other patients) of } \\
\text { such expressive writing. }\end{array}$ \\
\hline Akard et al. (5) & $\begin{array}{l}\text { Randomized, } \\
\text { controlled } \\
\text { intervention }\end{array}$ & USA & $\begin{array}{l}\text { Video narrative } \\
\text { construction } \\
\text { (digital } \\
\text { storytelling) }\end{array}$ & $\begin{array}{l}\text { Analyzing results with } 15 \text { experimental group and } 13 \text { control group } \\
\text { participants, this study determined that a legacy-making, digital } \\
\text { storytelling intervention for children with cancer was feasible and } \\
\text { fostered improvement in emotional and school functioning. }\end{array}$ \\
\hline Wilson et al. (6) & Literature review & USA & $\begin{array}{l}\text { Video narrative } \\
\text { construction } \\
\text { (digital } \\
\text { storytelling) }\end{array}$ & $\begin{array}{l}\text { A synthesis of findings from } 64 \text { publications, related to storytelling and } \\
\text { pediatric cancer, concluded that digital storytelling can be an } \\
\text { especially useful tool to promote social development, cultural } \\
\text { congruence, self-discovery, and self-understanding. }\end{array}$ \\
\hline Pereira (7) & $\begin{array}{l}\text { Controlled } \\
\text { intervention }\end{array}$ & USA & $\begin{array}{l}\text { Video narrative } \\
\text { construction }\end{array}$ & $\begin{array}{l}\text { Completion of a video therapy intervention resulted in significant } \\
\text { positive correlations with cancer patients' health-related behaviors, } \\
\text { personal relationships with individuals on their medical teams, their } \\
\text { perceived impact on others, and a sense of resilience and clarity } \\
\text { regarding their illness experience. }\end{array}$ \\
\hline Pereira et al. (8) & Qualitative analysis & USA & $\begin{array}{l}\text { Video narrative } \\
\text { construction }\end{array}$ & $\begin{array}{l}\text { Crafting a video narrative helped an adolescent leukemia patient gain } \\
\text { greater clarity about the overarching impact of cancer on his life and a } \\
\text { more positive attitude about accomplishing future goals. }\end{array}$ \\
\hline Pereira et al. (9) & $\begin{array}{l}\text { Exploratory } \\
\text { intervention }\end{array}$ & USA & $\begin{array}{l}\text { Video narrative } \\
\text { construction }\end{array}$ & $\begin{array}{l}\text { After examining content from video testimonials of } 25 \text { adolescent and } \\
\text { young adult cancer patients/survivors, video narratives seem to be an } \\
\text { effective means through which to explore thoughts and feelings about } \\
\text { the youth cancer experience. }\end{array}$ \\
\hline Schneider (2012) & $\begin{array}{l}\text { Exploratory } \\
\text { intervention }\end{array}$ & USA & Bibliotherapy & $\begin{array}{l}\text { Reading a disease-relevant story, entitled Nikki's Day at Chemo, } \\
\text { correlated with improved perceptions of intrapersonal functioning and } \\
\text { decreased physiological arousal among a cohort of pediatric } \\
\text { participants with cancer. }\end{array}$ \\
\hline $\begin{array}{l}\text { Thurneck et al. } \\
\text { (10) }\end{array}$ & Book chapter & USA & Bibliotherapy & $\begin{array}{l}\text { Bibliotherapy is a viable therapeutic approach for young people with } \\
\text { disabilities and healthcare needs, as it can help them (a) understand } \\
\text { their condition in a language comprehensible to them and (b) see that } \\
\text { they are not alone. }\end{array}$ \\
\hline $\begin{array}{l}\text { Malibiran et al. } \\
\text { (11) }\end{array}$ & Literature review & USA & Bibliotherapy & $\begin{array}{l}\text { An in-depth scrutiny of nine recent studies regarding bibliotherapy } \\
\text { provided preliminary evidence for its potential to mitigate symptoms of } \\
\text { depression, ineffective coping, and anxiety among cancer patients. }\end{array}$ \\
\hline
\end{tabular}

- "childhood cancer" "expressive writing"-141 results, 8 selected.

Only papers that featured pediatric patients and/or cancer survivors as their main subjects of verbal therapy interventions were selected (Figure 2). These papers were reviewed according to the following categories: study population (if applicable), description of intervention (if applicable), measures/methods (if applicable), and results/insights. Studies were analyzed for possible grouping themes, which ultimately emerged as talk therapy, expressive writing, video narratives, and bibliotherapy. Due to their novelty, lower cost, and higher possibility for acceptance and accessibility, we chose to focus on expressive writing, video narratives, and bibliotherapy in our final review.

Overall, half $(13 / 26)$ of the originally analyzed papers were ultimately excluded from our review as we adopted this narrower focus. Thirty-four other papers, either cited in the manuscripts above or suggested by the reviewers of this manuscript, were consequently analyzed and discussed. All provide supporting evidence for the utility of expressive writing, video narratives, 


\section{Sample Prompts for the Traditional Expressive Writing Paradigm}

\section{Day 1}

Today, your goal is to write your deepest thoughts and feelings about the trauma or emotional upheaval that has been influencing your life the most. As you write about this upheaval, you might begin to tie it to other parts of your life. How is this event related to who you have been in the past, who you would like to be in the future, and who you are now? Do not forget that this writing is for you and you alone.

\section{Day 2}

In your previous writing session, you were asked to explore your thoughts and feelings about a trauma or emotional upheaval that has affected you deeply. In today's writing, your task is to continue exploring your very deepest emotions and thoughts about that event, situation, or experience. You can write about the same trauma or upheaval as yesterday's, or you can choose a different one. Begin thinking about how this upheaval is, right now, affecting your life in general and perhaps whether you might be responsible for some of the effects of the trauma.

\section{Day 3}

In your writing today, focus on the same topics you have been examining or shift your focus to another trauma or to another feature of the same trauma. Your primary goal is to continue focusing and elaborating on your emotions, as well as the thoughts about those events that are affecting your life the most right now.

\section{Day 4}

This is the final day of the four-day writing exercise. As with the previous days' writings, explore your deepest emotions and thoughts about those upheavals and issues in your life that are most important and troublesome for you. In your writing, try to tie up anything that you haven't yet confronted. Really let go in your writing and be honest with yourself about this upheaval. Do your best to wrap up the entire experience into a meaningful story that you can take with you into the future.

FIGURE 1 | Sample prompts for the traditional 4-day expressive writing paradigm, asking participants to explore their deepest thoughts and feelings about a traumatic event or challenging experience. Adapted from Pennebaker and Evans (13) and created using BioRender.com.

and bibliotherapy exercises in our specific patient/survivor population of interest (pediatric oncology).

\section{RESULTS}

\section{Expressive Writing and Related Forms}

In 2018, Anzeneder et al. (48) conducted an EW study with four teenage brain tumor patients. The intervention consisted of four writing sessions, spaced 1 week apart, and participants completed three questionnaires (the Child Behavior Checklist, the Pediatric Quality of Life Inventory, and the Adolescent Coping Orientation for Problem Experiences) before, immediately after, and 1 month following its conclusion. Alongside data collected via the Linguistic Inquiry Word Count Program (which assesses the frequency of positive- or negative-affect words used by participants, like resilient or depressed), scores from these questionnaires helped quantify EW's effects on patients' coping skills, internalized symptoms, and perceived quality of life. Ultimately, the researchers found positive trends in each one of these variables for three out of four EW intervention participants. Given the extremely small sample size, replication studies with larger patient cohorts must be completed. At least for some pediatric cancer patients, however, Anzeneder et al.'s (2018) work does point to EW as an inexpensive, feasible, and meaningful verbal therapy.

In 2015, Chaparro (2) completed a similar study with 100 young adult survivors of childhood cancer and 88 of their mothers. First, Chaparro asked the 100 survivors to participate in a 20-min phone interview about their life story. Each participant was encouraged to think of their life as a book or as a novel and to identify key turning points therein. Pre- and postintervention responses on relevant questionnaires (assessing attachment style, posttraumatic growth, and psychosocial adjustment) were scored and compared, and all interview responses were coded for meaning making and coherence. Second, Chaparro asked the 88 mothers in the study to complete an EW task about a particularly challenging moment in their child's cancer experience. Before and after this task, each mother completed questionnaires about distress-related disclosure, "cancer talk" frequency, and dispositional optimism.

Overall, Chaparro found that meaning making was higher for cancer-related than for noncancer-related turning points 


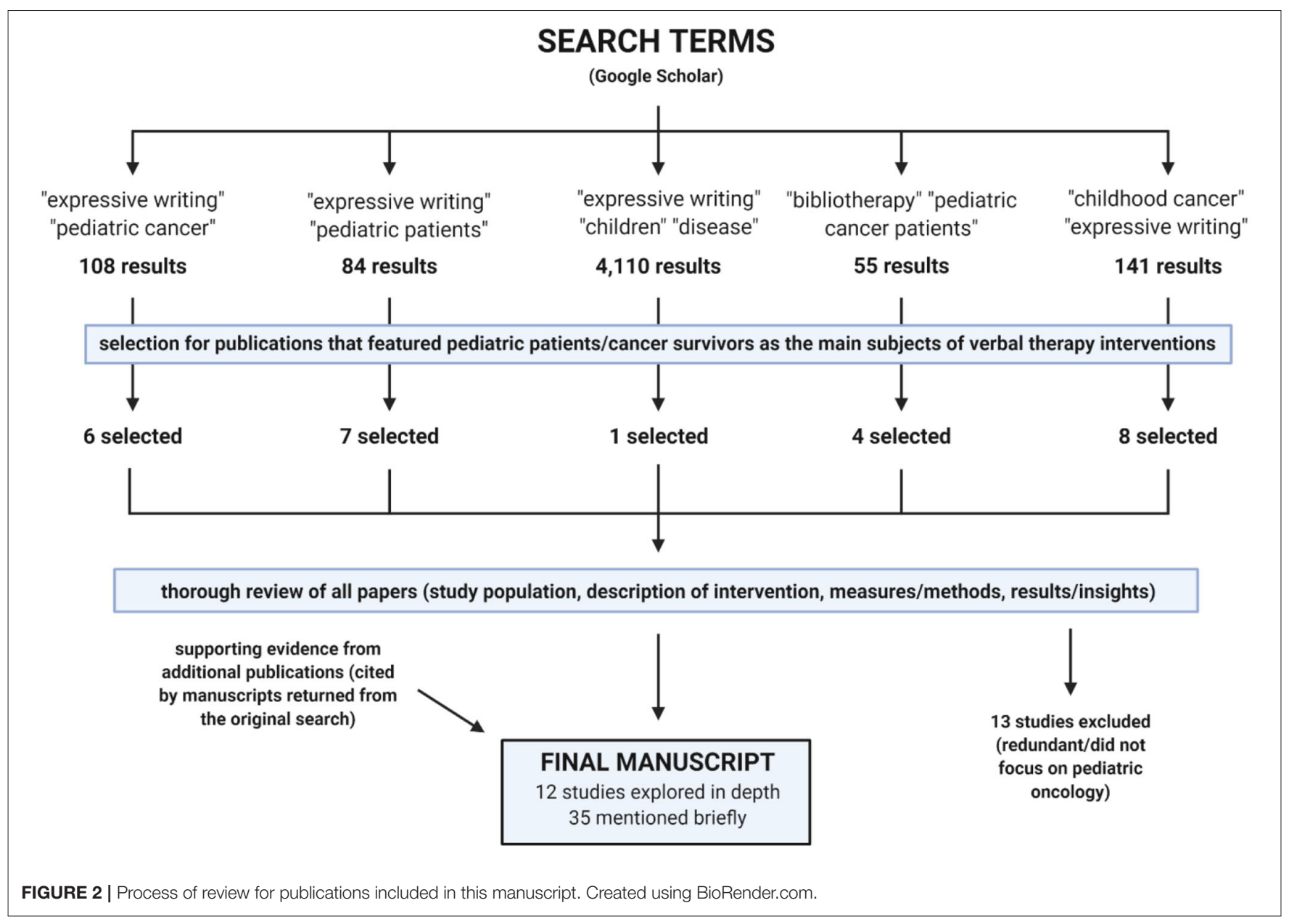

of survivors' narratives. Mothers' "cancer talk" frequency was positively associated with this meaning making, and mothers' distress-related disclosure also positively correlated with survivors' posttraumatic growth. For pediatric cancer patients, survivors, and caregivers, Chaparro posits that verbalizing one's cancer narrative can enhance psychological well-being, and she encourages future studies to be conducted on links between appropriate themes.

In line with this suggestion, Keim-Malpass et al. (3) recently explored seven illness blogs (focused on cancer disease progression) curated by self-identified adolescents with cancer (AWC). Using both a priori coding strategies and post hoc observations, key themes that emerged across these blogs included normalizing news, facing treatment failure, and reconciling chronos or treating time as an entity of which patients did not have enough. In normalizing news, the researchers noted that AWC often turned to self-deprecating humor and/or pragmatism when describing turning points in their cancer story (e.g., "I’ve been coughing [more] and whatever"; "It's back. My remission is over."). In facing treatment failure, AWC described profound transitions from periods of uncertainty into more active decision-making in their treatment plans (e.g., choosing to refuse or accept another round of chemotherapy). In reconciling chronos, patients tended to treat time like currency, hoping to buy more of it through palliative care options. Overall, Keim-Malpass et al. (3) conclude that each illness blog was an unparalleled outlet for its author to assert agency over their illness experience and tell their narrative in their own words. They assert that such EW-focused blogs are not just tools for patients' self-expression but also opportunities for healthcare professionals to understand the cancer experience through a patient's eyes-and to adjust their care accordingly. In the future, it would be interesting to explore how the themes that Keim-Malpass et al. (3) identified manifest among participants in other studies, as well as how we might tailor verbal therapy exercises to encourage discussion and reflection about them.

In 2017, Crook and Love (4) further explored themes across EW-inspired cancer blogs. Specifically, they examined a collective illness blog, evaluating advantages and disadvantages to participating in an online cancer support group. This group was frequented by over 6,000 AWC affected by cancer at any stage (diagnosis, treatment, or remission) and featured more than 20,000 posts discussing self-advocacy, frustration with the healthcare system, and when/how to disclose illness with others. A few disadvantages that the authors identified were both the potential to spread medical misinformation and 
the lack of synchronous communication (some posts can go uncommented upon or unanswered for months). However, a large advantage was that such collective, online EW offers necessary space for patients to write about their cancer experience and identify with others undergoing similar treatment regimens. EW, whether collective or not, can often be an unmatched avenue for cultivating self-acceptance and self-disclosure in pediatric oncology, and the studies from Anzeneder et al. (2018), Chaparro (2), Keim-Malpass et al. (3), and Crook and Love (4) support this in myriad, albeit sometimes subtle, ways.

\section{Video Narratives}

For some younger patients-especially those who are not yet literate or who may struggle to read and write (due to lethargy, "chemo fog," or other side effects of cancer treatment) - crafting video narratives may be a more appealing, yet equally as intriguing, option as EW for verbal therapy. In early 2015, two publications from Akard et al. (5) and Wilson et al. (6) attested to the power of digital storytelling. For their study, Akard et al. (5) completed a randomized video therapy intervention with 28 pediatric cancer patients; 15 answered questions about legacy-making and created a digital story about themselves, while the remaining 13 served as a control group (not answering any questions nor crafting a digital story with photographs, music, and video clips of themselves speaking). After the intervention, children in the experimental group reported slightly better emotional and school functioning than controls, and all experimental participants reported that the digital storytelling activity was enjoyable and fun. For their study, Wilson et al. (6) conducted a literature review of 64 publications at the intersection between storytelling and pediatric oncology. Ultimately, they concluded that digital storytelling, in particular, is a promising, modern approach to foster selfunderstanding, social development, cultural congruence, and self-discovery among pediatric cancer patients.

Pereira has substantiated the findings of the above studies with evidence from her video therapy work in pediatric oncology. In her first study (2017), Pereira (7) recruited adolescents with and without cancer to produce video narratives and answer questions about the videos they made. AWC were instructed to talk to the camera about their cancer experience, while control participants were asked to discuss a personal hardship they had faced in their life. Intriguingly, Pereira found that controls tended to address this personal hardship in a negative light, while AWC often referred to "silver linings" in their cancer experience. By offering an opportunity for AWC to recite their entire cancer story, video therapy brought a unique sense of resilience, clarity, and increased understanding of AWC's cancer experience overall. Significant positive correlations between reciting a personal narrative and participants' health-related behaviors, personal relationships with participants' medical teams, and participants' perceived impact on others were revealed.

For her second study (2017), Pereira et al. (8) filmed an adolescent leukemia patient as he recited his personal story since being diagnosed. Talking most in-depth about his access to quality medical care, the impact of cancer treatment on his overall health, his legacy as a cancer patient, and cancer's effects on his personal relationships, the patient was able to contextualize and come to a conclusion about his cancer story through video therapy. In the patient's own words, this video narrative exercise helped him gain greater clarity about the overarching impact of cancer on his life, as well as a more positive attitude about accomplishing future goals.

In a recent study (2020), Pereira et al. (9) asked nine survivors and 16 current patients of adolescent cancer to record a private video about their cancer experience. Content analysis identified self-esteem, missing social events, discomfort with the children's hospital environment, and frustration with the way healthcare providers spoke to them as predominant themes. Video therapy helped participants express their deepest feelings about such personal topics-and, in the future, could help healthcare providers learn how they can better serve AWC.

\section{Bibliotherapy Exercises}

As a third form of verbal therapy, bibliotherapy may be most appealing to shier/more reserved pediatric cancer patients, who wish to engage in a more passive activity: finding their own voice by reading about others with similar lived experiences. In 2012, Schneider (49) published her doctoral dissertation on a bibliotherapy intervention with 21 pediatric cancer patients. Participants were read the book Nikki's Day at Chemo and asked how they might apply some of the coping strategies discussed in the book to their own lives (for example, using one's imagination to cope with nervousness).

Postintervention, participants reported both high satisfaction with the book and statistically significant improvement within the measure of intrapersonal functioning. One child told Schneider: "having you read this book to me makes me want to write my own story that everyone can read," and one parent reported that it inspired her son to "speak more freely about his disease" with his healthcare team, his friends at school, and the general public. Schneider concludes that bibliotherapy is an inexpensive, convenient, and useful psychological intervention for pediatric cancer patients, and her findings are supported by publications on bibliotherapy for pediatric patients (10) and cancer patients (11) more generally.

In their 2007 book, Thurneck et al. highlight two key advantages of bibliotherapy for pediatric patients, either with cancer or without. One is that bibliotherapy can help pediatric patients understand their illness in a language comprehensible to them (e.g., with simpler words and with accompanying illustrations). The second is that illness-related intervention books can help patients with disabilities and/or who are critically ill see that they are not alone, especially if they use a lot of imagery and illustrations. Notably, cancer treatment often affects physical appearance, and body image difficulties are found across patients with diverse cancer sites (42). Bibliotherapy is one way to validate and address these challenges.

In support of this, Malibiran et al. (11) conducted a recent literature review of nine bibliotherapy interventions with a variety of cancer patients. (One of these interventions was Schneider's 2012 study.) Excitingly, the authors found that all nine interventions produced positive effects on patient variables including coping skills, anxiety, depression, self-esteem, and 


\section{Standards for the Psychosocial Care of Children with Cancer and Their Families}

\section{Standard 1}

Youth with cancer and their families should routinely receive systematic assessments of their psychosocial health care needs.

\section{Standard 2}

Patients with brain tumors and others at high risk for neuropsychological deficits as a result of cancer treatment should be monitored for neuropsychological deficits during and after treatment

\section{Standard 3}

Long-term survivors of child and adolescent cancers should receive yearly psychosocial screening for: a) adverse educational and/or vocational progress, social and relationship difficulties; b) distress, anxiety, and depression; and c) risky health behaviors. Adolescent and young adult survivors should also receive anticipatory guidance on the need for life-long follow-up health care.

\section{Standard 4}

Youth with cancer and their families should have access to psychosocial support and interventions throughout the cancer trajectory and access to psychiatry as needed.

\section{Standard 5}

Assessment of risk for financial hardship among pediatric oncology families should be incorporated at time of diagnosis. Targeted referral for financial counseling and supportive resources (e.g., governmental/charitable supports) should be offered as needed along with longitudinal reassessment and intervention.

\section{Standard 6}

Parents and caregivers of children with cancer should have early and ongoing assessment of their mental health needs. Access to appropriate interventions for parents and caregivers should be facilitated to optimize parent, child, and family well-being.

\section{Standard 7}

Youth with cancer and their families should receive individualized psychoeducation, information and anticipatory guidance related to disease, treatment, acute and long-term effects, hospitalization, procedures, and psychosocial adaptation.

\section{Standard 8}

Youth with cancer should receive developmentally appropriate preparatory information about, as well as psychological intervention for, invasive medical procedures.

\section{Standard 9}

Youth with cancer should be provided opportunities for social interaction during and after cancer treatment according to developmental level, preferences for social interaction, and health status.

\section{Standard 10}

Siblings of youth with cancer should be provided with appropriate psychosocial support services.

\section{Standard 11}

In collaboration with parents, school-age youth with cancer should receive school reentry support, focused on providing information to school personnel about the patient's diagnosis, treatment, and implications for the school environment.

\section{Standard 12}

Adherence should be assessed routinely and monitored throughout treatment.

\section{Standard 13}

Regardless of disease status, youth with cancer and their families should be introduced to palliative care concepts to reduce suffering. When necessary, individualized end-of-life and bereavement care plans should be developed.

\section{Standard 14}

A member of the health care team should contact the family after a child's death to assess family needs, identify individuals at risk for negative psychological sequelae, continue care, and provide resources for bereavement support

\section{Standard 15}

Open, respectful communication and collaboration between and among medical and psychosocial providers, patients, and families is essential.

FIGURE 3 | The 15 standards for the psychosocial care of children with cancer and their families, originally developed and relayed by Wiener et al. (46). Adapted from Wiener et al. (46) and created using BioRender.com.

interpersonal quality of life. Although the reviewed interventions largely took place with adults (rather than pediatric patients), these reportedly uniform benefits may suggest high efficacy and acceptability of bibliotherapy among cancer patients overall. More studies-with significantly larger sample sizes-should evaluate the effectiveness of bibliotherapy for pediatric cancer patients in decreasing feelings of stress, anxiety, depression, fear, and isolation.

\section{DISCUSSION}

Cancer is not just a physical illness; for many patients, it disrupts personal relationships, body image, mood regulation, and psychological well-being as well $(43,44)$. For pediatric cancer patients-who may experience a total loss of normal childhood-these challenges may be even more pronounced. Encouragingly, EW, video narratives, and bibliotherapy exercises work to validate and address such cancer-related difficulties. By approaching the illness experience through a narrative lens, these verbal therapies encourage patients to share their deepest thoughts and feelings about cancer and its broad impact on their lives. In contrast to traditional talk therapy (psychotherapy), these verbal therapies can also be delivered at little to no cost, anywhere, and completely on patients' own time. Here, we have reviewed twelve main studies on the utility of EW, video narratives, and bibliotherapy exercises in pediatric oncology. We urge future studies to further examine the efficacy of these techniques for pediatric cancer patients and survivors.

Naturally, however, a few limitations must be acknowledged. First, every study discussed in this review featured a relatively small sample size $(n \leq 100)$. Until further research is done, this small scope limits the generalizability of conclusions made about EW, video narratives, and bibliotherapy exercises in pediatric oncology. Second, not every study reviewed here was randomized and controlled nor were measures for specific outcomes (e.g., resilience) consistent across studies. In order to draw more robust conclusions about the effects that EW, video narrative construction, and bibliotherapy may have on depression, anxiety, and other psychological symptoms, outcome measures (i.e., measures that allow the efficacy of EW, video therapy, and/or bibliotherapy to be quantifiably assessed) must be standardized. These scorable measures may range from behavioral checklists to depression and anxiety questionnaires, but researchers must come to consensus on which ones must be utilized and reported in every study. This standardization will allow for more direct comparison of these verbal therapies' 
benefits across studies, environments, and even individuals. Not to be forgotten, such questionnaires and checklists must also all be appropriately scaled and written at appropriate reading levels for children and adolescents, rather than adults. Finally, it is important to acknowledge that EW, video therapy, and/or bibliotherapy may not be an effective therapeutic approach for every child or adolescent with cancer. Pennebaker and Evans (13) warn that re-exposure to a traumatic or challenging experience (like cancer treatment), either by writing or talking about it, may become overwhelming for some individuals. Healthcare teams, caregivers, and pediatric patients and survivors themselves should work together in weighing the potential long-term benefits of these verbal therapies against the feelings of distress they might initially provoke. In any case, careful consideration should be taken in determining what verbal therapy form may best suit each individual patient/survivor, as well as at which stage of their illness experience verbal therapies should/could be introduced.

In line with these suggestions, it is also important to address guidelines for the broader implementation of EW, video therapy, and bibliotherapy interventions on pediatric oncology wards. In 2018, Scialla et al. (45) surveyed leaders across 144 pediatric oncology programs on whether their psychosocial care practices were "state of the art." This referred to how integrated psychosocial care was with medical care and how closely it aligned with the Standards for Psychosocial Care for Children with Cancer and Their Families (Figure 3). Unfortunately, only half of all respondents agreed that their institution's psychosocial practices were "state of the art." Strikingly, psychosocial care (usually in the form of distraction, relaxation, and/or cognitive behavioral therapy) was also not universally provided to patients across programs-even when a problem was identified. EW, video narratives, and bibliotherapy exercises can increase the likelihood that, and shorten the time span in which, universal psychosocial care can be received. Hospitals and clinics could maintain a library of illness-related children's books and EW prompts for patients and families to use at their discretion. They might also permanently reserve a video camera in a private room,

\section{REFERENCES}

1. Patenaude AF, Kupst MJ. Psychosocial functioning in pediatric cancer. $J$ Pediatr Psychol. (2005) 30:9-27. doi: 10.1093/jpepsy/jsi012

2. Chaparro MP. Overcoming the Cancer Experience: Narrative Identity in Young Adult Survivors of Childhood Cancer. Toronto, ON:Doctor of Philosophy, University of Toronto (2015).

3. Keim-Malpass J, Stegenga K, Loudin B, Kennedy C, Kools S. "It's back! my remission is over": online communication of disease progression among adolescents with cancer. J Pediatr Oncol Nurs. (2016) 33:209-17. doi: $10.1177 / 1043454215600424$

4. Crook B, Love B. Examining the light and dark of an online young adult cancer support community. Qual Health Res. (2017) 27:938-48. doi: $10.1177 / 1049732316672638$

5. Akard TF, Dietrich MS, Friedman DL, Hinds PS, Given B, Wray S, et al. Digital storytelling: an innovative legacy-making intervention for children with cancer. Pediatr Blood Cancer. (2015) 62:658-65. doi: 10.1002/pbc.25337 so patients and survivors can verbalize and record their deepest thoughts and feelings on difficult days. If the individual chooses, this might be done without a mental health professional or family member present so that no external pressure is felt.

Our hope is that patients and survivors of pediatric cancer may be allowed time and opportunity for self-expression and self-reflection at any time in their illness experience. EW, video narratives, and bibliotherapy exercises are easily implementable and highly accessible options for this therapeutic endeavor. If desired, they may also be a powerful supplement to the professional follow-up (via music therapy, play therapy, and/or talk therapy initiatives) already offered at many institutions. Ultimately, "good health lies not just in the creative expression of a patient, but in the health of a system that recognizes the benefits of integrating the extremes of human experience into a sensible, organized, hopeful, [and] perhaps beautiful structure" (47). We firmly believe that the verbal therapies reviewed hereby encouraging storytelling, narrative construction, and getting in touch with one's self-do just this.

\section{AUTHOR CONTRIBUTIONS}

JJ and JE: concept and design. JJ: acquisition of data, analysis and interpretation of data, and manuscript preparation. JJ, JE, and RB: manuscript revision. All authors contributed to the article and approved the submitted version.

\section{ACKNOWLEDGMENTS}

The authors wish to thank Duke Bass Connections for connecting them to one another. The independent research conducted for this review was inspired by their 2018-2019 Bass Connections project team Expressive Writing for Resilience in Adult Pediatric Oncology Survivors and Their Caregivers. The authors also wish to thank Frontiers Fee Support, the Duke COPE Fund, and the Trent Center for Bioethics, Humanities \& History of Medicine at Duke University for funding this review's Article Processing Charge.

6. Wilson DK, Hutson SP, Wyatt TH. Exploring the role of digital storytelling in pediatric oncology patients' perspectives regarding diagnosis: a literature review. SAGE Open. 5:1-10. doi: 10.1177/2158244015572099

7. Pereira LM. Can Making Video Narratives Benefit Adolescents With Cancer. Palo Alto, CA:Doctor of Philosophy in Clinical Psychology, Pacific Graduate School of Psychology, Palo Alto University. (2017).

8. Pereira LM, Muench A, Lawton B. The impact of making a video cancer narrative in an adolescent male: a case study. Arts Psychother. (2017) 55:195201. doi: 10.1016/j.aip.2017.06.004

9. Pereira LM, Piela G, Dicola K. Thematic content of video narratives in patients and survivors of adolescent cancer. Psychooncology. 29:759-65. doi: $10.1002 /$ pon. 5340

10. Thurneck DA, Warner PJ, Cobb HC. Children and adolescents with disabilities and health care needs: implications for intervention. In: Prout HT, Brown DT, editors. Counseling and Psychotherapy with Children and Adolescents. Hoboken, NJ: John Wiley \& Sons, Inc. (2007). 
11. Malibiran R, Tariman J, Amer K. Bibliotherapy: appraisal of evidence for patients diagnosed with cancer. Clin J Oncol Nurs. (2018) 22:377-80. doi: 10.1188/18.CJON.377-380

12. Pennebaker JW, Beall SK. Confronting a traumatic event: toward an understanding of inhibition and disease. J Abnorm Psychol. (1986) 95:274-81. doi: 10.1037/0021-843X.95.3.274

13. Pennebaker JW, Evans JF. Expressive Writing: Words That Heal. Enumclaw, WA: Idyll Arbor, Inc. (2014).

14. Pennebaker JW. Opening Up: The Healing Power of Emotional Expression. New York, NY: Guilford (1997).

15. Pennebaker JW, Seagal JD. Forming a story: the health benefits of narrative. J Clin Psychol. (1999) 55:1243-54. doi: 10.1002/(SICI)1097-4679(199910)55:10<1243::AID-JCLP6>3.0.CO;2-N

16. Smyth JM. Written emotional expression: effect sizes, outcome types, and moderating variables. J Consult Clin Psychol. (1998) 66:174-84. doi: 10.1037/0022-006X.66.1.174

17. Halpert A, Rybin D, Doros G. Expressive writing is a promising therapeutic modality for the management of IBS: a pilot study. Am J Gastroenterol. (2010) 105:2440-8. doi: 10.1038/ajg.2010.246

18. Baddeley JL, Pennebaker JW. A postdeployment expressive writing intervention for military couples: a randomized controlled trial. J Trauma Stress. (2011) 24:581-5. doi: 10.1002/jts.20679

19. Meston CM, Lorenz TA, Stephenson KR. Effects of expressive writing on sexual dysfunction, depression, and PTSD in women with a history of childhood sexual abuse: results from a randomized clinical trial. J Sex Med. (2013) 10:2177-89. doi: 10.1111/jsm.12247

20. Laccetti M. Expressive writing in women with advanced breast cancer. Oncol Nurs Forum. (2007) 34:1019-24. doi: 10.1188/07.ONF.1019-1024

21. Gellaitry G, Peters K, Bloomfield D, Home R. Narrowing the gap: the effects of an expressive writing intervention on perceptions of actual and ideal emotional support in women who have completed treatment for early stage breast cancer. Psychooncology. (2010) 19:77-84. doi: 10.1002/pon.1532

22. Henry EA, Schlegel RJ, Talley AE, Molix LA, Bettencourt BA. The feasibility and effectiveness of expressive writing for rural and urban breast cancer survivors. Oncol Nurs Forum. (2010) 37:749-57. doi: 10.1188/10.ONF.749-757

23. Lu Q, Zheng D, Young L, Kagawa-Singer M, Loh A. A pilot study of expressive writing intervention among Chinese-speaking breast cancer survivors. Health Psychol. (2012) 31:548-51. doi: 10.1037/a0026834

24. Craft MA, Davis GC, Paulson RM. Expressive writing in early breast cancer survivors. J Adv Nurs. (2013) 69:305-15. doi: 10.1111/j.1365-2648.2012.06008.x

25. Lu Q, Yeung NC, You J, Dai J. Using expressive writing to explore thoughts and beliefs about cancer and treatment among Chinese American immigrant breast cancer survivors. Psychooncology. (2016) 25:1371-4. doi: 10.1002/pon.3991

26. Cook KE, Earles-Vollrath T, Ganz JB. Bibliotherapy. Interv Sch Clin. (2006) 42:91-100. doi: 10.1177/10534512060420020801

27. Newman K. Bibliotherapy as an Intervention for Aggressive Elementary Children. Provo, UT:Educational Specialist, Brigham Young University (2015).

28. Canatella E. The Effects of Bibliotherapy-Based Class Meetings on Students' Self-Concept and Perceptions of Peers. Baltimore, MD:Master of Education, Goucher College (2019).

29. Lewis KM, Amatya K, Coffman MF, Ollendick TH. Treating nighttime fears in young children with bibliotherapy: evaluating anxiety symptoms and monitoring behavior change. J Anxiety Disord. (2015) 30:103-12. doi: 10.1016/j.janxdis.2014.12.004

30. Hudak D. The therapeutic use of ball play in psychotherapy with children. Int J Play Ther. (2000) 9:1-10. doi: 10.1037/h0089437

31. Greer S, Moorey S, Baruch JDR, Watson M, Robertson BM, Mason M, et al. Adjuvant psychological therapy for patients with cancer: a prospective randomised trial. BMJ. (1992) 304:675-80. doi: 10.1136/bmj.304.6828.675

32. Goerling U, Foerg A, Sander S, Schramm N, Schlag PM. The impact of short-term psycho-oncological interventions onthe psychological outcome of cancer patients of a surgical-oncology department - a randomised controlled study. Eur J Cancer. (2011) 47:2009-14. doi: 10.1016/j.ejca.2011.04.031
33. Qiu J, Chen W, Gao X, Xu Y, Tong $\mathrm{H}$, Yang $\mathrm{M}$, et al. A randomized controlled trial of group cognitive behavioral therapy for Chinese breast cancer patients with major depression. I Psychosom Obstet Gynecol. (2013) 34:60-7. doi: 10.3109/0167482X.2013. 766791

34. Postone N. Psychotherapy with cancer patients. Am J Psychother. (1998) 52:412-24. doi: 10.1176/appi.psychotherapy.1998.52.4.412

35. Brown MR, Sourkes B. Psychotherapy in pediatric palliative care. Child Adolesc Psychiatr Clin N Am. (2006) 15:585-96. doi: 10.1016/j.chc.2006.02.004

36. Elwell L, Grogan S, Coulson N. Adolescents living with cancer : the role of computer-mediated support groups. J Health Psychol. (2011) 16:236-48. doi: $10.1177 / 1359105310371398$

37. Thompson CM, Crook B, Love B, Macpherson CF, Johnson R. Understanding how adolescents and young adults with cancer talk about needs in online and face-to-face support group. J Health Psychol. (2015) 21:2636-46. doi: 10.1177/13591053155 81515

38. Pan TM. Disclosure Experiences of Cancer Survivors Who Are in College. San Diego, CA:Master of Arts in Psychology, San Diego State University (2013).

39. Yi J, Kim MA, Akter J. How do they grow out of their cancer experience? Korean adolescent and young adult cancer survivors' stories. Ethn Health. (2019) 24:1-17. doi: 10.1080/13557858.2019. 1606164

40. Valizadeh L, Zamanzadeh V, Ghahremanian A, Musavi S, Akbarbegloo M, Chou F-Y. Experience of adolescent survivors of childhood cancer about self-care needs: a content analysis. Asia Pac J Oncol Nurs. (2020) 7:72-80. doi: 10.4103/apjon.apjon 47_19

41. Nitzburg GC, Farber BA. Patterns of utilization and a case illustration of an interactive text-based psychotherapy delivery system. J Clin Psychol. (2019) 75:249-61. doi: 10.1002/jclp.22718

42. Fingeret MC, Teo I, Epner DE. Managing body image difficulties of adult cancer patients: lessons from available research. Cancer. (2014) 120:633-41. doi: $10.1002 /$ cncr.28469

43. Erickson SJ, Steiner H. Trauma and personality correlates in long-term pediatric cancer survivors. Child Psychiatry Hum Dev. (2001) 31:195-213. doi: 10.1023/A:1026477321319

44. Moody K, Meyer M, Mancuso CA, Charlson M, Robbins L. Exploring concerns of children with cancer. Support Care Cancer. (2006) 14:960-6. doi: 10.1007/s00520-006-0024-y

45. Scialla MA, Canter KS, Chen FF, Kolb EA, Sandler E, Wiener L, et al. Delivery of care consistent with the psychosocial standards in pediatric cancer: current practices in the United States. Pediatr Blood Cancer. (2018) 65:1-17. doi: $10.1002 /$ pbc. 26869

46. Wiener L, Kazak AE, Noll RB, Patenaude AF, Kupst MJ. Standards for the psychosocial care of children with cancer and their families: an introduction to the special Issue. Pediatr Blood Cancer. (2015) 62:419-24. doi: $10.1002 /$ pbc. 25675

47. Montanaro RL. Creative Arts Therapy Programs for Pediatric Oncology Patients: A Comparative Case Study. Eugene, OR:Master of Art in Arts and Administration, University of Oregon (2007).

48. Anzeneder S, Secco DE, Mastronuzzi A, Colasanti AR, Gentile S. QOL-35. Expressive writing for adolescents with brain tumor: a case study. NeuroOncology. (2018) 20, i164.

49. Schneider NM. (2012). Bibliotherapy's Effect on Anxiety in Children with Cancer. Newberg, OR: George Fox University.

Conflict of Interest: The authors declare that the research was conducted in the absence of any commercial or financial relationships that could be construed as a potential conflict of interest.

Copyright (C) 2021 Jones, Evans and Barfield. This is an open-access article distributed under the terms of the Creative Commons Attribution License (CC BY). The use, distribution or reproduction in other forums is permitted, provided the original author(s) and the copyright owner(s) are credited and that the original publication in this journal is cited, in accordance with accepted academic practice. No use, distribution or reproduction is permitted which does not comply with these terms. 